\title{
Effect of HCV Eradication on Glycemic Control of Type 2 Diabetes Mellitus
}

Islam Ahmed Mohamed Sayed*1, Faried Fawzy Abd-elHafez ${ }^{2}$, Hatem Mahmoud Salem ${ }^{2}$

${ }^{1}$ Internal Medicine Department, AlAhrar Teaching Hospital, ${ }^{2}$ Internal Medicine Department,

Faculty of Medicine, Zagazig University, Egypt.

*Corresponding author: Islam Ahmed Mohamed Sayed Ahmed,

E-mail: _islamshalaby651@gmail.com, Mobile: (+02) 1022501130

\section{ABSTRACT}

Background: Hepatitis $\mathrm{C}$ virus (HCV) is a major cause of chronic liver disease, including cirrhosis and liver cancer. Type 2 diabetes mellitus (T2DM) is a common comorbid condition in approximately one-third of individuals with chronic HCV infection.

Objective: This study aimed at assessing the effect of the new direct acting antiviral drugs (DAAs) for chronic hepatitis $\mathrm{C}(\mathrm{HCV})$ on glycemic control of type $2 \mathrm{DM}$.

Patients and method: This prospective cohort study was done on 32 diabetic patients with hepatitis $\mathrm{C}$ in the Internal Medicine Department, Al-Ahrar Teaching Hospital. The patients underwent history taking, clinical examination and laboratory studies including routine investigations and fasting blood glucose and glycosylated hemoglobin before and after treatment with direct antiviral agents (DDAs).

Results: This study comprised 32 patients with diabetes. Their mean age was $57.65 \pm 7.67$ years. The females constituted $(62.5 \%)$. There was statistically non-significant difference change before and after treatment regarding TLC, total bilirubin, HcvAb or HBSAG. There was statistically significant change between before and after treatment regarding hemoglobin, platelet count, prothrombin time (all of them increased after treatment), INR, s.creatinine, ALT and AST (all of them decreased after treatment). There was statistically significant difference between PCR1 and PCR 2 before and after treatment. All patients had negative PCR after treatment with complete response to DDAs. There was statistically significant decrease between FBG after treatment while there is significant decrease in HbAlc after treatment.

Conclusion: HCV eradication leads to a statistically significant reduction in fasting glucose and $\mathrm{HbA} 1 \mathrm{c}$ in patients with type 2 diabetes, which is an indirect indicator of improvement of insulin sensitivity in patients with T2DM.

Keywords: HCV, DAAs, Glycemic, Diabetes Mellitus.

\section{INTRODUCTION}

Chronic hepatitis C (HCV) affects $1-2 \%$ of the world population and is a primary cause of liver morbidity and mortality including liver cirrhosis and hepatocellular carcinoma ${ }^{(\mathbf{1})}$. Insulin resistance (IR) is a feature of $\mathrm{HCV}$ infection reported up to $70 \%$ of cases and is involved in changes in glucose metabolism and in the development of type 2 diabetes mellitus (T2DM) that is observed with a higher prevalence in patients with $\mathrm{HCV}$ infection compared to non-infected subjects of $\mathrm{HCV}$-related liver disease and extra-hepatic manifestations ${ }^{(2)}$.

The landscape of HCV management is changing dramatically with the advent and approval of the new oral direct acting antiviral (DAA) medications ${ }^{(3)}$.

Several studies have also confirmed a multifold increase in the prevalence of glucose abnormalities in patients with $\mathrm{HCV}$ as compared to controls. As such, the virus has been implicated in the development of insulin resistance (IR) by modulating cellular gene expression and interfering with insulin signaling pathways ${ }^{(4)}$. T2DM remains a strong risk factor for HCC development in cirrhotics after sustained virologic response (SVR) has been obtained ${ }^{(5-6)}$, but a good glycemic control seems to reduce the incidence of $\mathrm{HCC}{ }^{(7-8)}$.

Treatment of $\mathrm{HCV}$ with direct-acting antiviral agents was associated with improved diabetes in a significant portion of patients with an average reduction in $\mathrm{HbAlc}$ of clinically significant magnitude ${ }^{(9)}$.

\section{AIM OF THE WORK}

This study aimed at assessing the effect of the new direct acting antiviral drugs (DAAs) for chronic hepatitis $\mathrm{C}(\mathrm{HCV})$ on glycemic control of types 2 DM.

\section{Ethical and patients' approval:}

A written informed consent was handled from the patients to contribute in the study. Approval for the research was gotten from Internal Medicine and Medical Biochemistry Departments, Zagazig University Hospitals after receiving Institutional Review Board (IRB) approval.
Study Design, Study Setting, and Study Participants:
A prospective cohort study was conducted in Internal Medicine Department at Al-Ahrar teaching hospital through the period from September 2018 to February 2019.
Sample size: It was calculated to be 32 cases as degree of improvement after $\mathrm{HCV}$ eradication on glycemic 
control of type $2 \mathrm{DM}$. There was $77.2 \%$ improvement compared to non-eradication $\mathrm{HCV}$ on glycemic control of type $2 \mathrm{DM}^{(\mathbf{1 0})}$ whom percentage was $22.8 \%$. Sample size was calculated using EPI info 6 with confidence level $95 \%$ and power $80 \%$.

\section{Inclusion criteria:}

A) Adult patients with type $2 \mathrm{DM}$, on oral hypoglycemic drugs with hepatitis $\mathrm{C}$ virus polymerase chain reaction (PCR) positive with compensated liver disease.

B) Age: between 18 years and 75 years.

Exclusion criteria: The exclusion criteria included patients with renal failure, heart failure, liver cell failure, cancer, connective tissue diseases, other endocrine disorders, or psychiatric disorders. Also, illiterate patients, critically ill patients due to any disease and pregnant or lactating women were excluded.

\section{Study Assessments and Data Collection:}

For each eligible patient, the following data were reported:

1. Complete history.

2. Full clinical examination.

3. Laboratory investigations:

Venous blood samples were withdrawn in the morning following overnight fasting. Sera were stored at $-80^{\circ} \mathrm{C}$ until examination. The routine laboratory investigations were done according to Clinical Pathology Department and laboratories of Zagazig University Hospitals' protocol and included

- CBC (hemoglobin concentration, WBC's count, platelet count and parameters), S. creatinine, liver function tests, coagulation profile, viral markers (HCV $\mathrm{AB}, \mathrm{HBsAg}$ ).

- Fasting blood glucose level and HbA1c before and after HCV treatment.
- Hepatitis C virus (PCR) quantitative before and after $\mathrm{HCV}$ treatment.

4. Radiological investigations including: Abdominal ultrasonography.

\section{Statistical Analysis:}

All data were collected, tabulated and statistically analyzed using SPSS version 20.0 for windows (SPSS Inc., Chicago, IL, USA) \& MedCalc 13 for windows (MedCalc Software bvba, Ostend, Belgium). Data were tested for normal distribution using the Shapiro Walk test. Qualitative data were symbolized as frequencies and relative percentages. Chi square test $(\chi 2)$ was used to compute difference between qualitative variables. Quantitative data were stated as mean \pm SD (Standard deviation). Mann Whitney test was used to compare medians of two groups (for nonparametric data).One way ANOVA test was used to compare between more than two dependent groups of normally distributed variables while Kruskal Wallis test ranks test was used for non-normally distributed variables. Pearson's and Spearman correlation tests were used for correlating normal and non-parametric variables respectively. Multivariate regression analysis (stepwise method) was performed to ascertain factors associated with sclerostin levels. All statistical comparisons were two tailed with significance Level of $\mathrm{P}$-value $\leq 0.05$ is significant and $\mathrm{p} \leq 0.001$ is highly significant difference.

\section{RESULTS}

The largest percentage of the studied patients were female $(62.5 \%)$. All had normal ECG while larger percentage of them had abnormal liver echopattern as appeared in abdominal ultrasonography. Their systolic blood pressure ranged from 90 to $130 \mathrm{mmHg}$ while diastolic blood pressure ranged from 60 to $90 \mathrm{mmHg}$ (Table 1).

Table (1): Demographic and clinical data of the studied cases.

\begin{tabular}{|c|c|c|}
\hline & No. & $\%$ \\
\hline $\begin{array}{ll} & \text { Sex: } \\
\text { - } & \text { Female } \\
-\quad & \text { Male } \\
\end{array}$ & $\begin{array}{l}20 \\
12 \\
\end{array}$ & $\begin{array}{l}62.5 \\
37.5 \\
\end{array}$ \\
\hline $\begin{array}{ll} & \text { ECG: } \\
-\quad & \text { Normal } \\
\end{array}$ & 32 & 100 \\
\hline $\begin{array}{ll} & \text { Pelviabdominal US: } \\
\text { - } & \text { Normal } \\
\text { - } & \text { Abnormal echopattern } \\
\text { - } & \text { Cirrhotic liver } \\
\text { - } & \text { Cirrhotic liver+HSM } \\
\end{array}$ & $\begin{array}{c}2 \\
25 \\
4 \\
1\end{array}$ & $\begin{array}{c}6.3 \\
78.1 \\
12.5 \\
3.1 \\
\end{array}$ \\
\hline & \multicolumn{2}{|c|}{ Mean+SD } \\
\hline Age (years) & \multicolumn{2}{|c|}{$57.65 \pm 7.67$} \\
\hline Systolic blood pressure (mmHg) & \multicolumn{2}{|c|}{$112.03 \pm 13.43$} \\
\hline Diastolic blood pressure (mmHg) & \multicolumn{2}{|c|}{$71.25+10.08$} \\
\hline
\end{tabular}

HSM: hepatosplenomegally 
Table (2): Laboratory data of the studied cases before and after treatment

\begin{tabular}{|c|c|c|c|c|c|c|}
\hline & & & Before & After & \begin{tabular}{|c} 
Paired \\
sample t. \\
test
\end{tabular} & p. value \\
\hline TLC & \multicolumn{2}{|c|}{ Mean \pm SD } & $7.05+1.81$ & $7.106+1.412$ & -0.392 & 0.698 \\
\hline Hb $(\mathrm{g} / \mathrm{dL})$ & \multicolumn{2}{|c|}{ Mean \pm SD } & $12.59 \pm 1.148$ & $13.434 \pm 1.11$ & -10.796 & 0.001 \\
\hline PLT & \multicolumn{2}{|c|}{ Mean \pm SD } & $176.18 \pm 6.95$ & $196.81 \pm 7.71$ & -7.003 & 0.001 \\
\hline PT & \multicolumn{2}{|c|}{ Mean \pm SD } & $82.63 \pm 14.74$ & $86.84 \pm 11.911$ & -5.618 & 0.000 \\
\hline INR & \multicolumn{2}{|c|}{ Mean \pm SD } & $1.16 \pm 0.15$ & $1.09 \pm .0948$ & 3.811 & 0.001 \\
\hline S.Create & \multicolumn{2}{|c|}{ Mean \pm SD } & $0.84 \pm 0.217$ & $0.80 \pm 0.182$ & 2.362 & 0.025 \\
\hline ALT (U/L) & \multicolumn{2}{|c|}{ Mean \pm SD } & $52.14 \pm 5.92$ & $39.19 \pm 2.58$ & 2.046 & 0.049 \\
\hline AST (U/L) & \multicolumn{2}{|c|}{ Mean \pm SD } & $51.75 \pm 6.057$ & $37.09 \pm 6.294$ & 2.566 & 0.015 \\
\hline $\begin{array}{c}\text { T.bilirubin } \\
(\mathrm{mg} / \mathrm{dL})\end{array}$ & \multicolumn{2}{|c|}{ Mean \pm SD } & $0.90 \pm 0.04$ & $0.85 \pm 0.03$ & 1.542 & 0.133 \\
\hline \multirow[t]{2}{*}{ HevAb } & \multirow[t]{2}{*}{ Positive } & No. & 32 & 32 & \multirow[t]{2}{*}{$0 \mathrm{MC}$ test } & \multirow[t]{2}{*}{1} \\
\hline & & $\%$ & 100.0 & 100.0 & & \\
\hline \multirow[t]{2}{*}{ HBSAG } & \multirow{2}{*}{ Negative } & No. & 32 & 32 & \multirow[t]{2}{*}{$0 \mathrm{MC}$ test } & \multirow[t]{2}{*}{1} \\
\hline & & $\%$ & 100.0 & 100.0 & & \\
\hline
\end{tabular}

There was statistically non-significant change before and after treatment regarding TLC, total bilirubin, HCVAb or HBSAG. There was statistically significant change between before and after treatment regarding hemoglobin, platelet count, prothrombin time (all of them increased after treatment), INR, creatinine, ALT and AST (all of them decreased after treatment) (Table 2).

Table (3): PCR1 and PCR 2 before and after treatment

\begin{tabular}{|c|c|c|c|}
\hline (d) & ( & Before & After \\
\hline $\begin{array}{l}\text { ICV.PCR. } \\
\text { Quant.1 }\end{array}$ & Mean \pm SD & $508954.63 \pm 56632.59$ & All negative \\
\hline
\end{tabular}

Table (4): Change in glycemic profile before and after treatment

\begin{tabular}{|c|c|c|c|c|c|}
\hline & & Before & After & $\begin{array}{c}\text { Paired } \\
\text { sample t. } \\
\text { test }\end{array}$ & p. value \\
\hline FBG & Mean \pm SD & $167.038 \pm 17.98$ & $144.94 \pm 41.736$ & 1.071 & 0.029 \\
\hline HbA1c & Mean \pm SD & $6.98 \pm 0.796$ & $5.83 \pm 0.567$ & 7.44 & 0.00 \\
\hline
\end{tabular}

There was statistically significant difference between PCR1 and PCR 2 before and after treatment. All patients had negative PCR after treatment with complete response to DDAs (Table 3). There was statistically significant decrease between FBG after treatment while there was significant decrease in HbA1c after treatment (Table 4).

\section{DISCUSSION}

Patients with Chronic HCV infection have significantly increased prevalence of T2DM, independent of liver disease stage compared to controls or HBV-infected patients. T2DM is a common comorbid condition in approximately onethirds of HCV-infected individuals, possibly due to a direct or indirect effect of the virus on insulin sensitivity ${ }^{(11)}$.

The females predominance detected in the current study agrees with previous study by Scavini et al. ${ }^{(12)}$. Several factors can interpret such findings. Females may be more likely to seek medical advice, sensitivity of random glucose and HbAlc may be higher among females than males ${ }^{(\mathbf{1 2})}$. This come in disharmony with previous studies ${ }^{(13-14)}$.
This study showed that there was statistically significant improvement in hemoglobin after treatment. This agrees with Hum et al. ${ }^{(10)}$ who aimed to investigate whether eradication of $\mathrm{HCV}$ infection with direct-acting antiviral (DAA) agents is associated with improved glycemic control in patients with diabetes. There was change in mean hemoglobin level before and after treatment. Ford $\boldsymbol{e t}$ al. ${ }^{(15)}$ conveyed that changes in mean hemoglobin concentration, before and after treatment affect HbA1c levels.

This study showed that, mean value of ALT and AST were statistically significant lower after treatment than before treatment of HCV. This comes in harmony with Abdel Alem et al. ${ }^{(13)}$. The enzyme 
alanine aminotransferase occurs primarily in liver cells. Ordinarily, this soluble enzyme is present at low levels in sera when liver function is normal. Elevated ALT values are usually seen in parenchymal liver diseases characterized by destruction of hepatocytes. ALT activity is more specific for the liver than AST and its increased serum concentrations are rarely observed in conditions other than parenchymal liver disease ${ }^{(16)}$. During and after treatment, there was statistically significant improvement of ALT and AST, whereas there was statistically significant progressive increase of platelets. These results agree with those reported by Radovanovic et al. (17) about normalization of alanine aminotransferase that predicts successful antiviral treatment in patients with chronic hepatitis $\mathrm{C}$, which showed strong association between normal ALT values and SVR (70.6 vs. $72.6 \%$, respectively), which confirms similar results of a previous study ${ }^{(\mathbf{1 8})}$. Moreover, a recent report from Korea showed that normalization of ALT was a useful response predictive factor for viral elimination not only for SVR but also for a rapid viral response after 4 weeks of treatment ${ }^{(\mathbf{1 9})}$. Moreover, the same was reported by Reddy $\boldsymbol{e t}$ al. ${ }^{(20)}$ where statistically significant improvements, from baseline to post-treatment week 4 , were observed in albumin, ALT, AST, bilirubin, and platelet counts $(\mathrm{P}<0.001)$ for all patients with genotype $1 \mathrm{HCV}$ infection and compensated cirrhosis treated with ledipasvir and sofosbuvir.

The significant decrease in serum creatinine, after treatment in the current study is in line with Hum et al. ${ }^{\left({ }^{10)}\right.}$. Mean value of INR after treatment (1.09) compared to (1.16) at before treatment. This is in agreement with Stine et al. ${ }^{(21)}$.

The statistically non-significant change in TLC and total bilirubin noticed here agrees with the study of Hashim et al. ${ }^{(22)}$.

In this study, clearance of $\mathrm{HCV}$ induced a significant improvement in glycemic control among patient with type 2 diabetes, as demonstrated by the reduction of FG and HbA1c levels. This comes in the same line with Ciancio et al. ${ }^{(23)}$ who studied change in FG and HbA1c values before and after therapy with direct-acting antivirals (DAAs) in $122 \mathrm{HCV}$ patients with type 2 diabetes mellitus. They conveyed that 110 of the recruited patients with chronic hepatitis C and T2DM, were treated with DAAs and 12 remained untreated. A total of 101 patients obtained a SVR (Group 1), while nine were relapsers. Group 2 (21 patients) composed of the nine relapsers and the 12 untreated patients. A significant reduction of mean FG $(134.3 \pm 41.32$ $\mathrm{mg} / \mathrm{dL}$ vs $152.4 \pm 56.40 \mathrm{mg} / \mathrm{dL}, \mathrm{P}=0.002)$ and HbA1c values. In Group 1, 20.7\% of patients could reduce or suspend their antidiabetic therapy compared to none in group $2(\mathrm{P}=0.03)$, despite the significant weight increase observed in group 1 . SVR induced a significant amelioration of glycemic control in diabetic HCV-patients, despite of the significant weight increase. Recent preliminary reports suggest that DAA agents are associated with improvement of fasting glucose (FG) and glycated hemoglobin $(\mathrm{HbA} 1 \mathrm{c})$ values during and after therapy in diabetic patients ${ }^{(24-25)}$.

It is reasonable to hypothesize that a successful eradication of $\mathrm{HCV}$ would improve clinical outcomes in patients with T2DM as reported by a previous study ${ }^{(26)}$. Boughton et al. ${ }^{(27)}$ showed that good glycemic control preoperatively may protect against the harmful effect of T2DM on infection and is associated with a reduced risk of readmission to intensive care unit and a reduced length of stay in hospital. Morales et al. ${ }^{(28)}$ who assessed the effect of sofosbuvir (SOF) based regimens on glycemic control in a retrospective analysis of hepatitis $\mathrm{C}$ virus (HCV)-infected patients treated and cured with SOF regimen [SOF/ribavirin/interferon, $\mathrm{SOF} /$ simeprevir, or SOF/ledipasvir (LDV) \pm ribavirin] from January 2014 to March 2015. HbA1C checked before and after treatment, of which 22 had the diagnosis of DM type 2. HbA1C significantly decreased with treatment of HCV (pretreatment $6.66 \% \pm 0.95 \%$ vs post-treatment $6.14 \% \pm 0.65 \%, \mathrm{P}<0.005)$.

\section{CONCLUSION}

We concluded that $\mathrm{HCV}$ eradication leads to a statistically significant reduction in fasting glucose and $\mathrm{HbAlc}$ in patients with type 2 diabetes which is an indirect indicator of improvement of insulin sensitivity in patients with type 2 DM.

This study had some limitations including lack of control group, relatively small sample size and short follow up period.

Financial resources: The authors did not receive any fund or grant. The research is self-funded.

Conflict of interest: The authors declared no conflict of interest.

\section{REFERENCES}

1. Axley P, Ahmed Z, Ravi S et al. (2018): Hepatitis C Virus and Hepatocellular Carcinoma: A Narrative Review. J Clin Transl Hepatol., 6 (1): 79-84.

2. Adinolfi LE, Nevola R, Guerrera B et al. (2018): Hepatitis $\mathbf{C}$ virus clearance by direct-acting antiviral treatments and impact on insulin resistance in chronic hepatitis C patients. J Gastroenterol Hepatol., 33: 1379-1382.

10. Fried MW, Buti M, Dore GJ et al. (2013): Once-daily simeprevir (TMC435) with pegylated interferon and ribavirin in treatment-naive genotype 1 hepatitis $\mathrm{C}$ : the randomized PILLAR study. Hepatology, 58: 1918-29.

11. Dai CY, Yeh ML, Huang CF et al. (2015): Chronic hepatitis $\mathrm{C}$ infection is associated with insulin resistance and lipid profiles. J Gastroenterol Hepatol., 30: 879-884 
12. Hedenstierna $M$, Nangarhari $A$, Weiland $O$ et al. (2016): Diabetes and cirrhosis are risk factors for hepatocellular carcinoma after successful treatment of chronic hepatitis C. Clin Infect Dis., 63: 723-729.

13. Donadon V, Balbi M, Valent F et al. (2010): Glycated hemoglobin and antidiabetic strategies as risk factors for hepatocellular carcinoma. World J Gastroenterol., 16: 3025-3032.

14. Van der Meer AJ, Feld JJ, Hofer H et al. (2017): Risk of cirrhosis-related complications in patients with advanced fibrosis following hepatitis $\mathrm{C}$ virus eradication. J Hepatol., 66: 485-493.

15. Arase Y, Kobayashi M, Suzuki F et al. (2013): Effect of type 2 diabetes on risk for malignancies includes hepatocellular carcinoma in chronic hepatitis C. Hepatology, 57: 964-973.

16. Gilad A, Fricker ZP, Hsieh A et al. (2019): Sustained Improvement in Type 2 Diabetes Mellitus is Common After Treatment of Hepatitis C Virus With Direct-acting Antiviral Therapy. J Clin Gastroenterol., 53 (8): 616-620.

17. Hum J, Jou JH, Green PK et al. (2017): Improvement in Glycemic Control of Type 2 Diabetes after Successful Treatment of Hepatitis C Virus. Diabetes Care, 40 (9): 1173-1180.

18. Basaranoglu $M$, Basaranoglu G (2011): Pathophysiology of insulin resistance and steatosis in patients with chronic viral hepatitis. World J Gastroenterol., 17: 4055-4062.

19. Scavini M, Christine A. Stidley et al. (2003): Prevalence of Diabetes Is Higher Among Female than Male Zuni Indians. Diabetes Care, 26 (1): 55-60.

20. Abdel Alem S, Elsharkawy A, Fouad R et al. (2017): Improvement of glycemic state among responders to Sofosbuvir-based treatment regimens: Single center experience. Journal of Medical Virology, 89 (12): 21812187.

21. Niu Z, Zhang $\mathbf{P}$, Tong $Y$ (2016): Age and gender distribution of hepatitis $\mathrm{C}$ virus prevalence and genotypes of individuals of physical examination in WuHan, Central China. Springerplus, 5: 1557-1559.

22. Ford ES, Cowie CC, Li C et al. (2011): Iron-deficiency anemia, noniron-deficiency anemia and HbA1c among adults in the US. J Diabetes, 3: 67-73.

23. Limdi J, Hyde G (2003): Evaluation of abnormal liver function tests. Postgrad Med J., 79: 307-312.

24. Radovanovic-Spurnic A, Pavic S, Bojovic $\mathrm{K}$ et al. (2016): Normalization of alanine aminotransferase predicts successful antiviral treatment in patients with chronic hepatitis C. SM Liver J., 1: 1001-3.
25. George SL, Bacon BR, Brunt EM et al. (2009): Clinical, virologic, histologic, and biochemical outcomes after successful HCV therapy: a 5 year follow-up of 150 patients. Hepatology, 49: 729-738.

26. Kim YJ, Jang BK, Kim ES et al. (2012): Rapid normalization of alanine aminotransferase predicts viral response during combined peginterferon and ribavirin treatment in chronic hepatitis $\mathrm{C}$ patients. Koearn $\mathrm{J}$ Hepatol., 18: 41-47.

27. Reddy KR, Bourlière M, Sulkowski M et al. (2015): Ledipasvir and sofosbuvir in patients with genotype 1 hepatitis $\mathrm{C}$ virus infection and compensated cirrhosis: an integrated safety and efficacy analysis. Hepatology, 62: 79-86.

28. Stine JG, Wynter JA, Niccum B et al. (2017): Effect of Treatment with Direct Acting Antiviral on Glycemic Control in Patients with Diabetes Mellitus and Chronic Hepatitis C. Ann Hepatol., 16: 215-220.

29. Hashim AE, Kandeel HT, Hendy OM et al. (2017): Effect of new direct-acting antiviral drugs on insulin resistance and glycemic control after treatment of chronic hepatitis $\mathrm{C}$ virus infection in type 2 diabetic patients. AlAzhar Assiut Med J., 15: 187-95

30. Ciancio A, Bosio R, Bo S et al. (2017): Significant improvement of glycemic control in diabetic patients with $\mathrm{HCV}$ infection responding to direct-acting antiviral agents. Journal of Medical Virology, 90 (2): 320-327.

31. Pavone P, Tieghi T, D'Ettorre G et al. (2016): Rapid decline of fasting glucose in $\mathrm{HCV}$ diabetic patients treated with direct-acting antiviral agents. Clin Microbiol Infect., 22 (5): 462-3.

32. Fabrizio C, Procopio A, Scudeller L (2017): HCV and diabetes: towards a "Sustained" glycaemic improvement after treatment with DAAs? Clin Microbiol Infect., 23: 342-343.

33. Coppo C, Bonfanti D, Bo S (2015): Risk of microangiopathy in type 2 diabetes mellitus patients with or without chronic hepatitis $\mathrm{C}$. Results of a retrospective long-term controlled cohort study. Dig Liv Dis., 47: 405410 .

34. Boughton C, Mustafa O, Suddle A (2016): Good glycaemic control pre-operatively protects against adverse outcomes associated with diabetes in liver transplant recipients. Hepatology, 64: 493-495.

35. Morales AL, Junga Z, Singla MB et al. (2016): Hepatitis $\mathrm{C}$ eradication with sofosbuvir leads to significant metabolic changes. World Journal of Hepatology, 8 (35): 1557-1563. 